MARTT RAPOLA

\title{
Reunamerkintöjä Juhana Cajanuksen virren julkaisuasuihin
}

Satunnainen kompastus, vähäinenkin, voi joskus aiheuttaa tosiasioiden näyttäytymisen harhaanjohtavassa valossa, kunnes erehdys jostakin syystä paljastuu. Niin tässäkin. Monipuolisesti valaisevassa. ja runon syvää ymmärtämystä ilmentävässä tutkielmassaan 'Juhana Cajanuksen virsi", joka ilmestyi Virittäjässä 1914 102_114, V. Tarkiainen mainitsi, että käsittelynalainen runoelma on "tarkasti alkutekstin mukaan painettuna" V. Tarkiaisen ja O. J. Brummerin toimittamassa teoksessa "Poimintoja vanhemmasta suomalaisesta kirjallisuudesta" ss. 33-35. Tästä lukemistosta oli silloin olemassa

ensimmäinen, v. 1913 ilmestynyt painos. Vaikka kirjasta myöhemmin saatiin neljä uutta painosta, näyte esiintyi jatkuvasti samanlaisena. Myös Tarkiaisen väite näytteen ja alkutekstin tarkasta samanlaisuudesta säilyi tarkoin entisenä, kun mainittu Virittäjän tutkielma F. 1922 ilmestyi toistamiseen kirjassa "Piirteitä suomalaisesta kirjallisuudesta". Tarkiainen lienee antanut ohjeet runon jäljentämisestä "Poimintoihin" jollekulle, joka ei neuvoa seuratessaan ollut riittävän huolellinen. Julkaistu näyte ei näet ole v. 1683 ilmestyneen alkuperäisen mukainen. Sanoisin, että se poikkeaa siitä huomattavasti. Eikä Tarkiainen nähtävästi myöhemminkään tullut kiinnittäneeksi asiaan huomiotansa.

Tarkiainen kertoo tutkielmansa toisessa alaviitteessä, että v. 1683 ensi kerran painettu runo "otettiin sitten hiukan muutettuna vuoden 1701:n virsikirjaan". Kirjassaan "Suomalaisen virsikirjan virret" (1936) s. 634 Kustaa Hallio puolestaan sanoo: "Vähin muutoksin virsi tuli 1700 virsikirjaan". Nämä ovat kuin kaikua Julius Krohnista, joka r. 1866 oli käyttänyt sanoja "sitten vähän muutet- 
tuna otettiin virsikirjaamme" ("Helmivyö suomalaista runoutta" s. 7). Miten muutosten vähyyden laita lieneekin, ilmeistä on, että se asu, joka "Etkös ole ihmisparka" -1'unolla on Tarkiaisen ja Brummerin lukemistossa ja - lisättäköön - myös A. V. Koskimiehen "Agricolasta Juteiniin" -antologiassa (1926) ss. 208-210 sekä V. A. Hailan ja Eino Kauppisen "Sanan mahti" -kirjan I osan ss. 70-72 (2. p. 1952) on sana sanalta ja likipitäen muoto muodolta sama kuin Vanhan virsikirjan virrellä 278 vuodesta 1701 a $1 \mathrm{ka}$ en. Alkutekstiä vastaamattomia ovat niinikään "Suomen Runotar"- ja "Suomalainen Parnasso"- antologioissa Juhana Cajanuksen kuuluna runona julkaistut näytteet. Nekin perustuvat Vanhan virsikirjan säilyttämään muotoon, vaikka niiden asua on luettaruussyistä normaalistettu.

Asiallisesti 1683-vuoden arkkijulkaisua noudattaviakin on, ensiksikin Hallion mainitussa teoksessaan ss. 632-633 julkaisema, jossa on vain muutamia vähäpätöisiä ortografisia poikkeamisia siitä. Vastikään (1959) olen omaan "Vanhan kirjasuomen lukemistooni" ss. 119-121 ottanut tämän 'hengellisen veisun maailman katoavaisesta menosta" alkuperäisestä arkista. Lisäksi muistettakoon tässä yhteydessä Julius Krohnin kielellisesti ja ortografisesti normalisoitu, mutta alkuperäistä tekstiä läheltä noudatteleva laitos kokoelmassa "Helmivyö suomalaista runoutta" 1866 sekä E. N. Setälän tai V. Tarkiaisen vastaavanlainen alkumuodon tulkinta "Suomen Kansalliskirjallisuus" -sarjan IV osassa ss. 349-354. Ja vihdoin: Tarkiaisen tutkielmaan sisällytetyt näytteet ovat — toisin kuin 'Poimintojen" teksti — kauttaaltaan alkuarkista tarkasti lainattuja. Samaa on sanottava Rafael Koskimiehen käyttämistä runositaateista hänen tutkielmassaan "Juhana Cajanus, kuoleman runoilija" ("Runoilijoita ja kiistamiehiä" 1926).

Erehtyminen on inhimillistä, eikä puheeksi tulleen, Tarkiaiselle sattuneen virheellisen maininnan oikaiseminen olisi tämänkäänvertaisen julkisuuden arvoinen, ellei asiaan kytkeytyisi muutakin. Kuten nähtiin Krohn, Tarkiainen ja Hallio käyttivät sanontoja "vähän muutettuna", "hiukan muutettuna", "vähin muutoksin". Ilmeisesti asiaa on pidetty niin vähäpätöisenä, että kukaan tutki- 
joista ei ole kunnolla vaivautunut selvittämään itselleen tehtyjen muutosten todellista luonnetta. Itse väitin Vanhan virsikirjan toisinnosta, että se poikkeaa alkuperäisestä "huomattavasti". Vanhan virsikirjan kokoonpano- ja muotoutumisvaiheitten selvittelijä Onni Kurvinen (Vanha virsikirja, 1941), joka olisi voinut esiintyä asiassa erotuomarina, ei ole ensinkään siihen puuttunut. Riippuu tietysti kokonaan siitä, mihin puoleen asiaa huomionsa kiinnittää, näkeekö siinä todettavat muutokset vähäisinä vai huomattavina. Minäkin yhdyn edeltäjiini siinä, että Vanhasta virsikirjastakin luettuna Juhana Cajanuksen virsi välittää varsin väkevästi ne tunnot, joiden sanalliseksi ilmennykseksi runon alkumuoto kerran on purkautunut nuoren, kuoleman aavistuksiin vaipuneen tiedemiesrunoilijan ahdistuksesta. Jos kohdistamme tarkkaavaisuutemme lähinnä yksityisten sanojen ja erinäisten kieliopillisten muotojen muutoksiin, korjailu merkitsee tuskin ainoassakaan kohdassa ratkaisevaa tai olennaista sävyn ja sisällyksen vaihtumista. Ortografisiin pikkueroihin kajoamatta luettelen seuraavassa näkyvimmät (kunkin tapauksen jäljessä on säkeistön järjestysnumero).

Coscas itket ylen öitä $>$ Ettäs itket yli öit (1)

Coscas suret suuttumata $>$ Ettäs suret suuttumata (1)

Catzo caicki catzeltawat, cunneltawat $>$ Catzos caicki catzeldawat, cunlleldavat (4)

Eikö löydy loppuwia > Eikö löyttä loppuwij (4)

Mitä Puusa pijscuttapi, cuiscuttapi $>$ Mitä puusa pijscuttapi, cuicuttapi (6)

$S e$ se Linnun lendäwängi $>S a a$ se linnun lendäwängin (7)

Hauwin hirmuisen Cwwusa $>$ Hawwin hirmuisen kidas (9)

Syöstä, haasta, särke, sorta $>$ Syöxe, haasta, särke, sorta (3)

Catzo caicki catzeltawat $>$ Catzos caicki catzeldawat (4)

Ongo ilımet jos sä caadut $>$ Ongos ihmet? jos sä caadut (19)

Puut eij pääse paxu Juuret $>$ Puut ei pääse, paxut juuret (10)

Caatahan casotesansa > Caatahan caswaesans (10)

Täm' on ikä ihanalla Auringolla > Tämä ikä ihanalla, auringolla (15)

Etzi meno muuttumatoin, puuttumatoin $>$ Etzi meno muuttumatoind, puuttumatoind (21)

Hauwin Haut' on cuohuwasa Cattilasa > Hauwin Haut' on Cattilosa cuohuwasa (9)

Eij nijn wälä woimatoinda, Wäetöindä > Ei nijn wälä wäetöindä, woimatoinda (12)

Vähäistä, toisarvoista - myönnettäköön. 
Se mikä kuitenkin tekee Vanhan virsikirjan alias Tarkiaisen ja. A. V. Koskimiehen lukemistojen, "Suomen Runottaren" ja "Stromalaisen Parnasson" esittämän version mielestäni huomattavasti alkutekstistä eroavaksi, jopa niin, että sopii kysyä, onko alkuperäisen. innoituksen aitous enää tallella, piilee runomitan erään yksityiskohdan järjestelmällisessä vaihtumisessa. Siihen ei nähdäkseni ole kiinnitetty sen ansaitsemaa, tokko vähäistäkään huomiota. On katsottu silmät sokeiksi Cajanuksen runon ja Lars eli Lasse Lucidorin hautausvirren yhteiseen metrumiin - siitäkin huolimatta, että kaikki Cajanuksen tutkijat ovat tunteneet alkuperäisen arkin ja että Tarkiainen otti tutkielmansa sitaatit siitä, samalla kun hän julkaisi toisaalla muuttuneen version. "En märkelik likhet både i anseende till meter och tankar", lausui jo 1819 Mnemosynen anonyymi kirjoittaja (s. 66). "Yhteinen värsymittakin", kirjoitti Julius Krohn 1862 ("Suomenkielinen Rumollisuus Ruotsinvallan aikana"s. 76), ja "Onhan ulkoasu - runomitta, säerakenne ja loppusointujärjestys — molemmissa ilmeisesti samanlainen", Tarkiainen 1914 (Virittäjä 106). Runon alkumuodon kaavassa on kuitenkin pakko havaita aivan olennainen, ei missään nimessä sattumanvarainen eroavuus, jos sitä. vertaa Lucidorin vastaavaan:

$\begin{array}{cc}\text { Cajanus: } & \text { Lucidor: } \\ \begin{array}{c}\text { Etkös ole Thmis parca } \\ \text { aiwan arca }\end{array} & \text { Usle menskobarn betrakta } \\ \text { Coseas itket ylen öitä } & \text { Märk och akta } \\ -\cup|-\cup|-\cup \mid-u & \text { Hur ostadigt Verlden står } \\ -\cup|-\cup|-\cup \mid-u & -\cup|-\cup|-\cup \mid-u \\ & -\cup|-\cup|-\cup \mid-\end{array}$

Toisin sanoen yhtä säännöllisesti kuin sekä kolmas että kuudes säe Lucidorin jokaisessa 16 säkeistössä on katalektinen, molemmat Cajanuksen 23 säkeistössä päättyvät täyteen trokeiseksi tulkittavaan runojalkaan. Juhana Cajanus toisin sanoen poikkesi täsmälleen 46 kertaa esikuvasta, joka kaikessa muussa näyttäisi sanelleen hänen rytmityksensä. Tämän on täytynyt tapahtua täysin tietoisesti, sanoisin lisäksi: määrätietoisesti. Mutta hänen tarkoitustaan tajuamatta henkilö — olipa hän sitten Erik Cajanus tai joku muu — joka. 
muokkasi hänen perinnöstään Vanhan virsikirjan n:on 278, ei tyytỵnyt arkkivirren poljentoon. Hän lienee kuunnellut runoa jonkin ennakkotottumuksen, ehkä juuri Lucidorin virren, lisäksi ehkä tuntemansa koraalisävelmän varassa, ${ }^{1}$ ja tämän johdosta säkeistön kaava samastui Lucidorin noudattaman kanssa. Tahti muuttui, kun säkeistön ratkaisevimmissa rajakohdissa, kolmannen ja kuudennen säkeen lopussa, suoritettiin erilaisin keinoin tavun poisto, esim. öitä $>$ öit, pelcurilla $>$ pelcureill, powesa $>$ powes, menoja $>$ menenoi, pitäpi $>$ pitä, kestänepi $>$ kestäne jne. Näin saatiin aikaan toisinto, jonka useimmat tällä vuosisadalla julkaistut antologiat esittävät Juhana Cajanuksen tuotteena. Myös virallinen virsikirja on eri uudistusvaiheissaan (Lönnrot 1867, sitten 1886 ja 1938) seurannut Lucidorin rytmilinjaa.

Oliko Juhana Cajanuksella sitten jokin erityinen tavoite antaessaan säkeistöjensä ratkaisevien rytmirajojen poiketa käsillä olleesta mallista? Vastaan myönteisesti ja perustelen kantaani seuraavin näkökohdin.

Juhana Cajanuksen taidokas ja runsas alkusoinnun viljely on ilmeinen, siihen ei ole suotta kiinnitetty huomiota: 'Runsaasti ja aistikkaasti käytetty alkusointu nivoo säkeitä toisiinsa ja antaa niille toisinaan järeän, toisinaan lyyrillisen pehmeän kaiun" (Tarkiainen, Virittäjä 1914 112). Lukuunottamatta lyhyitä "puolisäkeitä", jotka usein ovat yksisanaisia, koko virressä on vain yksi täysin alkusoinnuton säe ("Pyri taiwahan ilohon"). Sen lisäksi siinä on 8 säettä, joissa vähintään kaksi sanaa alkaa eri vokaalein, mitä myös pidetään alkusointutavoittelun merkkinä. Kun ottaa huomioon, että virsi on kauttaaltaan joskin epätasaisesti riimitetty ja että siinä lisäksi on sisäsoinnunkin tapauksia, voi sanoa, että sointukeinoja on käytetty suorastaan tuhlailevasti. Vähemmänkin alkusoinnuttelun olisi luullut riittävän, ellei Juhana Cajanuksen olisi katsottava mielessään hahmotelleen ja myös suoranaisesti tavoitelleen uutta, mutta silti vanhaan suomalaiseen runomuotoon liittyvää stroofia. Ja tästä

1 1 Me laulamme nykyisin "Etkös ole"-virttä 1600-luvulta periytývällä sävel-' mällä. 
johdumme siihen, mikä selittää ei vain kyseisten taitekohtien säkeidèn (säkeistön kolmannen ja kuudennen) kahdensantavuisuuden; vaan myös erään runossa usein toistuvan poljentoseikan, jonka Tarkiainen on käsittänyt puutteeksi: "Jos sanakorko joskus joutuukin polkeuksiin (esim. cuole|mán kä| sistä, couril|lá co|willa, pudo|tá pi|täpi, maan po|wéhen), ei sitä ole kummeksittava, sillä vielä Ahlqvistin aikoina 1850- ja 1860-luvuilla esiintyi samanlaista taitamattomuutta." Tarkiaiselta jäi mainitsematta, että hänen neljä esimerkkiään edustavat kaiken kaikkiaan 22:ta samanlaista tapausta Cajanuksen virren piirissä, joten "taitamattomuus", jos siitä tosiaankin olisi kyşmys, olisi yllättävän laaja-alaista. Perättäin Iueteltuina tarkoittamani säkeet ovat seuraavat (ortografia nykyistetty):

a) Luojan laitok-sen pe-rähän

Syöstä, sullo' maan po-vehen

Hirmu kouril-la ko-villa

Kaiken maail-man me-noja

Maaksi muuttu-a pi-täpi

Puusta pudo-ta pi-täpi

Kovan kuole-man kä-sistä

Kuin on kalal-la me-resä

Vetten karjan-kin ve-desä

Hauvin hirmui-sen ku-vusa

Toinen puhu-van po-vesa

Hänen tiedus-tat ta-pansa

Tämä tähte-in pe-sällä

Tämän maail-man me-noisa

Luojan luotu-in se-asa

Sinun synti-sen pi-täisi

Täsä turha-sa ti-lasa

Pyydä taiva-han ta-lohou

Pyri taiva-han i-lohon

b) Kaata-han ka-sotesansa

Tyhjäk-si ta-vattomaksi

c) Käänny käskyl-lä ko-valla

Runon alkuperäisen muodon ja virsikirjan virren vertailun kannalta on tähdellistä huomata, että 22 tapauksesta kokonaista 21 (muut paitsi luetteloni viimeinen) edustaa säkeitä, jotka v. 1700 operoitiin tavua lyhyemmiksi. Mutta mitä silloin tapahtui? Lie- 
neekö Tarkiaiselta todella jäänyt huomaamatta, että hänen "virheellisinä" pitämänsä säkeet voidaan esteittä ja estoitta lukea sanapainoa polkemattakin? Kun niin menetellään, niin käsissämme on kaunis sarja puhdaspiirteisiä kalevalanmittaisia säkeitä, nimenomaan noita "piristäviä", Matti Sadeniemen luokittèlun mukaan B- ja C-tyyppeihin luettavia - 'Mieleni minun tekevi", "Saa'ani sanelemahan" —, joiden yhteenlaskettu prosenttisuhde eräissä tutkituissa kansanrunoryhmissä vaihtelee 48,6-50.2 Cajanuksen virren 92 nelipolvisesta trokeesäkeestä siis $23,9 \%$ olisi kyseistä B-resp. C-tyyppiä, kun taas muut kuuluisivat, jos vertailua kalevalanmittaiseen halutaan jatkaa, Sadeniemen luokittelun A-tyyppiin: "Vaka vanha Väinämöinen", "Sepä loihe laulamahan" jne. Tämän kalevalaisen perusarkkitehtuurin tuntomerkit on hävitetty Vanhan virsikirjan samoin kuin uudempienkin vastaavista laitoksista (1886 n:o 395, 1938 n:o 455). Peruuttamaton vahinko - tekee mieli sanoa on tapahtunut. En ole varsinaisessa tutkimustyössäni tottunut arvioimaan sen osuuden merkitystä, mikä rytmillä — vanhaa runoutta ajatellen nimenomaan metrumilla - on runon kokonaishahmolle, sen ilmeelle ja sen sanoman oikealle avautumiselle, siksi en tiedä, erehdynkö kun otaksun, että Juhana Cajanuksen joutsenlaulun poljentoon kajottaessa jotakin hänen inspiraatioonsa olennaisesti kuulunutta on särjetty.

Viivähdettäköön vielä kysymyksessä liikutaanko tosioloisella pohjolla, jos Cajanuksen virren metrumi yritetään tulkita kalevalanmitasta lähtien. Yleisemminkään ei vanhimman suomalaisen taidelyrïkan muotojen kehitystä tutkittaessa vastaavaa kysymystä voida siyuuttaa. Kalevalanmitta ei ole väistynyt kädenkäänteessä. Eino Salokas on teoksessaan 'Maallinen arkkirunoutemme Ruotsin vallan aikana" (1923) esittänyt huomioita vanhan runomitan piirteiden säilymisestä ja turmeltumisesta vanhan käännös- ja mukailurunouden piirissä, ja Toivo Haapanen on tutkimuksessaan "Suomalaiset runomittateoriat 1800-luvulla" (1926) joutunut jopa samaan käsitykseen Cajanuksen ''korkoa polkevista". säkeistä kuin tämän kir-

2 Materi Sadenifmi, Die Metrik des Kalevala-verses, 1951, ss. $17,20-21$. 
joittaja. Hän lausuu sivulla 28: "ainakin yhdessä tapauksessa [koronpolkeminen on] katsottava vanhan runomitan aiheuttamaksi, joka sillä välin oli yhä yleisemmin tullut taiderunoudessa käytäntöön. Juhana Cajanuksen virressä 'Etkös ole ihmis parka' on runsaasti sellaisia säkeitä kuin

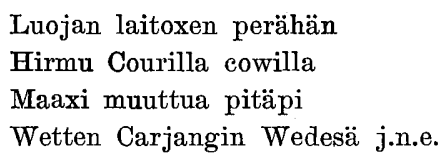

jotka ilmeisesti johtuvat vanhasta runomitasta." Omalta osaltani esitin v. 1934 Kalevalaseuran vuosikirjassa vastaavanlaisen esimerkin ("Vanhan runon kuvastelua parissa 1500-luvun suomalaisessa virressä" KVK 14 149-169, erityisesti ss. 163-168). Parissa aiheeltaan vanhoihin latinankielisiin, nelipolvista trokeeta noudatteleviin kirkkolauluihin palautuvassa virressä, joiden käsikirjoitukset ajoittuvat $1580: \mathrm{n}$ vaiheille mutta ilmeisesti edustavat asteittaisen muotokehityksen tulosta, on luonteenomaisimpina piirteinä pantavissa merkille alkusointu, kerto ja "kalevalaisittain vaihteleva". poljento. Jambisäkeitä luovista yksitavuisista säkeenalkusanoista huolimatta trokeinen rakenne paistaa säilyneen muodon läpi, eikä ole vaikeata lukea loppuheittoon päättyvien säkeiden takaa täysiä trokeejalkoja. Esim.

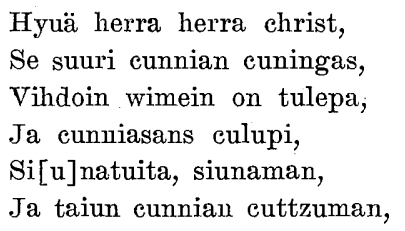

on väkivaltaa tekemättä palautettavissa - ja uskoakseni palautuukin suunnilleen seuraavaan alkurunoiluun:

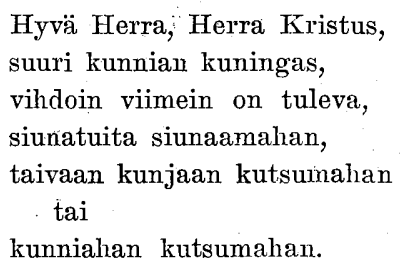


Loppusointujen pujottelu vanhaan kudelmaan oli tärkein keino, jolla runotyötä yritettiin mukauttaa ajan muotivaatimuksiin.

Juhana Cajanuksen virsi muodostaa mitä mielenkiintoisimman rinnakkaistapauksen mainituille sata vuotta vanhemmille virsille. Hänkin kuuntelee ensi sijassa vanhaa kotoista runolaulua - ei hän ollut suotta syntynyt ja kasvanut Paltamon runomailla vaikka hänet on opetettu seuraamaan modernimpaakin tahtia. Hänen kaikki "täydet" säkeensä ovat nelipolvista trokeeta, ja yhtä lukuunottamatta kaikissa on toteutettu alkusoinnun vaatimus. N. $24 \%$ toteuttaa erityisesti juuri kalevalanmitalle ominaisen "murron", kuuluu ts. Sadeniemen luokitteluun B-, osaksi C-tyypin säkeisiin. Lisäksi hänellä on runsas enemmistö "luonnollisia" trokeisia nelipolvisäkeitä, jommoisten käyttelyyn vanhimmat suomalaista runomittaa muka noudattelevat runoilijat olivat joukolla langenneet. Lienee syytä pikipäin tarkastella, miten Cajanus on onnistunut näiden, ns. A-tyyppiä olevien säkeiden sepittelyssä.

Tarkkoja ollaksemme on myönnettävä, että jo Cajanuksen B-tyypin piiristä löytää kolmisen esimerkkiä kalevalaisen kestosäännön rikkeestä :

\author{
Puusta pudota pitäpi \\ Cuin on Calalla Meresä \\ Toinen puhuwan powesa
}

Mutta runon kaikki kysymykseen tulevat säkeet ja runojalkojen nousut lukuun otettuina (nelipolvisten säkeiden ensimmäisen jalan jätän laskuista pois, kyseisiä trokeita on kaikkiaan 368) tapausten määrä osoittautuu melkoiseksi. Olen laskenut kaikkiaan 47 runojalkaa, joissa lyhyt pääpainollinen vastoin tunnettua sääntöä on sijoitettuna nousuun: Etkös ole, ylen öitä, suret suuttumata, Parcu pojes paneminen, Coreana cukasansa, Mik' on ilo oleskella, asuskella, Etzi muuta elandota, olendota jne. Suhteellisesti määrittäen 47:368 merkitsee n. 12,8 \%:ia. (Jos "puolisäkeet" pudotetaan laskuista jää jäljelle 276 runojalkaa, joistá 35 :ssä on lyhyt pääpainollinen nousutavu, suhde likipitäen sama kuin edellisessä tapauksessa.) Mutta kun muistamme, että vanhan suomalaisen runomitan sääntöjä ei 1600-luvulla vielä tunnettu, niin ahkerasti kun sitä yritettiinkin mukailla korvakuulon varassa, sanotunlaista ei tarvitse ihmetellä. 
Jos oli varsinaisen kalevalanmitan käyttäjissä joku hyväkin taitaja, kuten Mattias Salamnius, niin runsaammin oli heikkoja, esim. Erik Justander, Pärttyli Vhael, Henrik Lilius, Calamniukset (isä ja poika), Simo ja Henrik Achrenius, Kristfrid Ganander. On aivan luonnollista, että Juhana Cajanuksen omia uriaan aukova runo, jossa "vanha suomalainen" on ollut muotokeinojen lähteistä vain yksi, tosin ilmaisun kieleen vankimmin ankkuroitu, mitan vaatimusten seuraamisessa varsinkin tasaisissa A-tyypin säkeissä jäi epätyydyttäväkssi. Eihän Cajanuksen liioin onnistunut välttää pitkien vokaalien sijoittamista laskuihin, esim. infinitiiveissä haasta(a), särke(e), sorta(a), murta(a), preesensin yks. 3. persoonan muodoissa käändy, culke, wäändy, wyöry, poicke, pyöry, caatu, partitiiveissa toiwo(o), wähä(ä) tai muodoissa ei coskan, catowasa. Yksikirjaiminen ortografia tavallaan kätki painottoman tavun vokaalin todellisen keston.

Cajanuksen loppusointujen tarkastelu jää sen näkökulman ulkopuolelle, josta olen lähtenyt hänen runoaan valaisemaan. Tarkiainen on todennut, että niissä ei ole kehumista (Virittäjä 1914 112). Runon sisällyksen anti on niin mahtava, että muotorikkeet eivät sanottavasti häiritse. Mielisin kuitenkin loppusoinnuissa havaittujen aruttomuuksien huomioitsijalle viitata tapauksiin, joissa B-tyyppisen säkeen kolmitaruinen loppusane osallistuu eräänlaisen riimin muodostamiseen A-tyyppisen säkeen lopun kanssa. Kieltämättä Cajanus on tähän tavoitteeseen tähdännyt, vaikka tulos vaikuttaa kauttaaltaan väkinäiseltä. Mutta lukija tämmöistä tuskin huomaakaài. Miksi? Hän liukuu näihin runoriveihin ympätyn loppusoinnuttelun ohi, sillä asianomaiset säkeet tyydyttävät hänen muodon tajunsa pelkän rytminsä ansiosta — siinä näet tuntee "kalevalaisen":

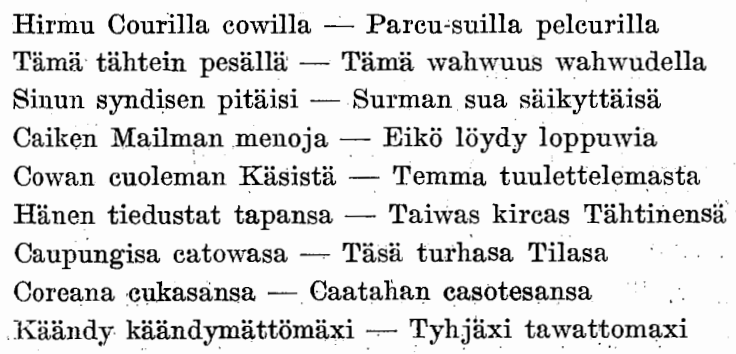


Juhana Cajanuksen virsi antaa vakavaa ajattelemisen aihetta kaikille niille, jotka joko todellisen tarpeen pakottamina tai vain mielijohteesta suorittelevat menneiden aikojen runotuotteitten korjailua oman aikansa kieli- ja makuvaatimuksia vastaavammiksi. Puuttumatta tähän asiaan periaatteen kannalta esitän muutaman reunamuistutuksen niihin lukutapoihin, joita Cajanusta normaalistạneet julkaisijat ovat noudattaneet toisen sạkeistön viimeistä ja kolmannen ensimmäistä riviä muka selventääkseen. Alkumuodossa. sanotaan:

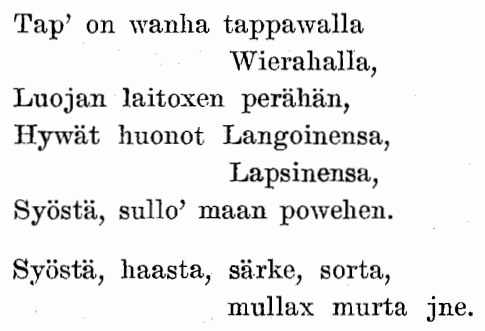

Vanhaan virsikirjaan tuli aluksi

Syöstä, sulloo maan poween.

Lukuun ottamatta säkeen lopun tavuluvun muutosta toinen sana: oli saanut lähinnä ortografiselta vaikuttavan silittelyn osakseen. Miten se nähtävästi on käsitetty, siitä antaa viitteen seuraavan säkeen korjaus :

Syöxee, haastaa, särkee jne.

Siis inf. syöstä oli vaihtunut indik. prees. 3. p. muotoon syöksee. Ja että sama ajatus on omituisesti kätkeytynyt jo edellisen rivin: tulkintaan, se ilmenee virsikirjan myöhemmistä painoksista, joissa tavataan:

Syöstää, sulloo ja syöksee, haastaa.

Julius Krohn selvensi ajatusta Helmivyössä näin:

Syöksee, sulloo ja Syöksee, haaskaa (!), mikä uuden ajatustavan kannalta olikin luonnollista.

Suomen Kansalliskirjallisuus palasi kuitenkin (IV 349, 1930) Vanhan virsikirjan myöhäisempään lukutapaan ja kirjoitti

Syöstä̈, sulloo

mutta omaksui jälleen uuden lisäpiirteen sikäli, että pani syöstää 
muodon myös siihen, mihin virsikirja oli vaihtanut syöksee-muodon, siis

$$
\text { Syöstää, haastaa, särkee sortaa jne. }
$$

En puutu haastaa verbin mielivaltaiseen vaihtamiseen muka ymmärrettävämpään haaskaa (Krohn, "Suomen Runotar"). Sen sijaan haluan tähdentää, että Cajanuksen kaikki kyseisten rivien verbimuodot olivat "infinitiivejä. Suorasanaisiksi selvennettyinä nämä säkeet sisälsivät tämän: tappavalla vieraalla on vanha tapa syöst ̈̈, sulloa maan poveen, syöstä, haastaa, särkeä jne. Vanhan virsikirjan korjaaja, jonka tilillä on virren alkuperäisrytmin turmeleminen, on viimeistään kolmatta säkeistöä korjaillessaan päästänyt tajunnastaan alkuperäisen rakenteen, jossa oli infinitiiviattribuuttien kasautuma, ja sommitellut uuden finiittilauseen tajunnassa väikkyneen, mutta muodollisesti ilmaisematta jääneen subjektin ('tappava vieras') varaan, johon hänen predikaattinsa syöksee viittaa. Tätä erehdystä on uudessa toimitusvaiheessa seurannut toinen: Edellinenkin syöstä on pitänyt tajuta ind. preesensiksi, mikä on johtanut tekaistuun muotoon syöstää (virsikirja, "Suomen Kansalliskirjallisuus", "Suomen Runotar"). Julius Krohn on kapinoinut tätä vastaan ja sijoittanut tälänkin muodon syöksee.

Kukaan korjaajista ei ilmeisestikään ole kiinnittänyt huomiota Cajanuksen kirjoitustapaan Syöstä, sullo'. Jälkimmäisen sanan heittomerkki on täysin ylksiselitteinen. Vanha ortografiamme ei ole milloinkaan käyttänyt sellaista pitkävokaalisen preesensmuodon jäljessä, ei Cajanuskaan. Hänen säkeessään se on kiistämätön merkki siitä, että tähtäimessä on ollut normaali infinitiivimuoto sulloa, jonka hän paltamolaisena tunsi paremmin kuin useimmat suomea silloin kirjoittelevat, ja sen lyhentämisestä runomitan vaatimusten mukaiseksi hän on tällä kirjoitustavalla tahtonut huomauttaa lukijalleen.

MartTi Rapola: Einige Randbemerkungen zu den verschiedenen Fassungen des Kirchenliedes von Johan Cajanus

Der Schwanengesang des im Jahre 1681 im Alter von 25 Jahren verstorbenen Johan Cajanus "über die Vergänglichkeit dieser Welt". (das Kirchenlied "Etkös ole Thmis parca" usw.) gilt als hervorragendstes Erzeugnis der finni- 
schen Lyrik während der Schwedenherrschaft (vor dem Jahre 1809). Das Lied hatte 23 Strophen mit dem interessanten Schema:

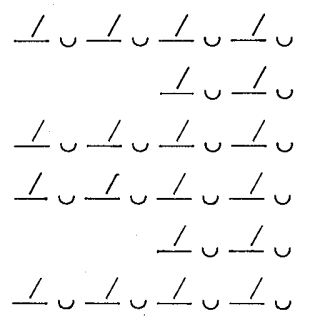

Metrisch und motivisch sind Einflüsse aus dem von dem Schweden Lars Johanson (Lucidor) in den 60er Jahren des 17 . Jh. verfassten Begräbnisgesang festgestellt worden. Cajanus' Lied erschien als Sonderdruck im Jahre 1683 und wurde in das Gesangbuch der finnischen Kirche vom Jahre 1701 (das sogenannte "Alte Gesangbuch", das im Jahre 1886 offiziell abgeschafft wurde) aufgenommen. In den Neuauflagen des Gesangbuches wurde das Lied zurechtgestutzt, so dass die Fassung aus dem Jahre 1886 schon merklich und die Verstümmelung von 1938 mit ihren 12 Strophen ganz wesentlich vom Original abwichen. Nichtsdestoweniger wird als Verfasser auch des jüngsten Liedes ohne Vorbehalt Johan Cajanus genannt.

Schon bei der Aufnahme des Liedes in das Gesangbuch wurde das Versmass verändert, wodurch der letzte Versfuss des dritten und sechsten Verses katalektisch wurde. Hier lehnte man sich offensichtlich an Lucidors obengenanntes Lied an. Man war der Ansicht, dass die Änderungen auf den Gedankenund Gefühlsgehalt des Liedes nicht eingewirkt hätten; hingegen aber wurde die alte finnische Festigkeit des Ausdrucks dabei schlimm zugerichtet, und dieser Umstand hatte im Hinblick aufs Ganze eine gewisse Bedeutung. Cajanus hatte nämlich seine 8-silbigen Verse dem alten Kalevala-Versmass nachgebildet. Ein grosser Teil der jetzt aus 8-Silbern zu 7-Silbern verstümmelten Verse latte im rhythmischen Bewusstsein Cajanus' zu dem Verstyp der Volksdichtung gezählt, den Matti Sadeniemi (FFC 139 17) den B-Typ nennt: "Maaxi muuttua pitäpi", Schema Łu亡uuúuu. Sie wurden verunstaltet und verstiessen - vielleicht auch beim Sprechen, vor allem aber nach einer Choralmelodie gesungen -- gegen den natürlichen Wortdruck: "Maaksi muuttu-á pi-tấä." — Der älteste Bearbeiter des Liedes beging auch einige Deutungsfehler, die sich seither erhalten haben. Es ist bedauernswert, dass Cajanus' Lied in einigen unserer meistbenutzten Anthologien (Tarkiainen-Brummer "Poimintoja", A. V. Koskimies "Agricolasta Juteiniin", J. V. Lehtonen u.a. "Suomen Runotar") in der aus dem Alten Gesangbuch stammenden entstellten Form ersehienen ist. 